\title{
The significance of Escherichia coli in the upper respiratory tract of children under 2 years of age
}

\author{
JOHN D. BARRIE \\ M.D., Dip.Path. \\ JAMES B. GALLACHER \\ M.B., Ch.B. \\ Microbiology Department, Fife Area Laboratory, Hayfield Road, Kirkaldy KY2 $5 A G$
}

\begin{abstract}
Summary
Colonization of the upper respiratory tract of neonates by Gram-negative bacilli (especially Escherichia coli) is not rare, and the incidence declines after 1 year of age. It is believed that the likelihood of colonization increases with the length of stay in hospital at the time of birth, and that such colonization does not reflect any pathological process. Evidence has not been found to support the view that the use of antibiotics is the reason for colonization in neonates (the situation in adults or children over 2 years of age is not considered here). The authors believe that the birth canal is not an important source of Gram-negative bacillary flora but that perineal contact at birth and maternal handling after birth more probably are, especially in the hospital environment where Gram-positive organisms have been suppressed by hexachlorophane.

With the limited range of $E$. coli typing sera available, a relatively high proportion of non-typeable strains was found. Among those which did type, the incidence of various strains corresponded fairly closely to those which are known to occur in the normal bowel and to cause urinary infections. No evidence for typespecific respiratory pathogenic strains was found.
\end{abstract}

\section{Introduction}

The isolation of Gram-negative bacilli from sputum cultures can pose a problem in interpretation for the clinical bacteriologist. Wilson and Martin (1972) attempted quantitative assessment analogous to that now widely accepted for urinary pathogens. The significance of the predominantly Gramnegative bacillary flora obtained from the respiratory secretions of young children newly admitted to hospital with chest infections has also been debated. Such culture findings are certainly very different from those described as normal in standard text-books (Topley and Wilson, 1964), yet there is considerable reluctance among both clinicians and bacteriologists to regard coliform bacilli as pathogenic in these situations. It has been suggested that such flora develops after the child has received antibiotics, and the studies of Elderkin et al. (1965), Shallard and Williams (1966) and Farmer (1968) on children in hospital lend some support to this view. The authors' experience in general practice and hospital laboratory led them, quite independently, to believe that this explanation was not altogether satisfactory, and they were sufficiently interested in the subject to arrange a combined clinical-laboratory study. They were further influenced in the overall planning of their study by the conclusions published in two other papers. Firstly, McCall and Acheson (1968) noted that the combined effects of the seasonal and age patterns of admission for respiratory infections brought about significant differences in the morbidity experience of children born in different seasons. The authors were interested to see whether a similar pattern of Gram-negative bacillary colonization of infants of the same age would emerge. Secondly, Court (1968) stressed the importance of a fuller understanding of the epidemiology of respiratory disease, and pointed to the need for studies in families and other defined communities to achieve a more comprehensive picture of the total incidence and clinical range of respiratory illness and the agents causing it. Brimblecombe et al. (1958) produced an excellent survey of this sort in a working-class area of London, and Lidwell and Sommerville (1951) carried out similar work in a country village.

With Court's last point particularly in mind, the objects of the present study were to establish the frequency of Gram-negative bacilli in the respiratory secretions of children when healthy and when suffering from respiratory infections, and to search for possible relationships between such colonization and neonatal and environmental factors.

\section{Methods}

The survey included 114 consecutive infants born to mothers in one practice and, of this number, ninety were followed for 2 years. The practice (list 3700 ) was centred on three mining villages and the surrounding farming countryside. The specimens consisted of samples of respiratory secretion collected on bacteriology swabs made of non-absorbent cotton wool. The back of the tongue was depressed until the child 'gagged' or coughed to produce the secretions. It was usually impossible to avoid contact with the surrounding fauces. The swab was then placed in 
Stuart's transport medium and taken to the laboratory, where it was plated on horse blood agar, heated blood (chocolate) agar and MacConkey agar. These media were incubated at $37^{\circ} \mathrm{C}$ for $18 \mathrm{hr}$. Lactose fermenting colonies of typical morphology were recorded as Escherichia coli. Mucoid colonies which fermented inositol were classified as species of Klebsiella. Spreading, non-lactose fermenting colonies were recorded as Proteus spp. Gram-negative bacilli which did not fit into this simple scheme were classified as 'other coliforms'. Organisms recorded as Haemophilus influenzae showed characteristic features on chocolate agar, were both $\mathrm{X}$ and $\mathrm{V}$ factordependent and were non-haemolytic. Those included under the heading 'other Haemophilus' comprised haemolytic $\mathrm{X}$ and $\mathrm{V}$ factor-dependent strains and both haemolytic and non-haemolytic varieties which were V-dependent. Detailed biochemical and serological identification was undertaken only in certain instances (see below).

Swabs were collected from each child, whether born in hospital or at home, according to a fixed pattern. They were taken on the 5th, 7 th, 14 th, 21 st and 28th day of life, and thereafter at monthly intervals. In all cases of respiratory infection swabs were taken before treatment and at the end of the illness. The nature and duration of antibiotic therapy was noted. Records were also established to show home or hospital delivery, maturity at birth, nature of delivery and type of membrane rupture, and the use of chemotherapy in the last 2 weeks of gestation, in labour and in the post-natal period. The number of ante-natal days spent by the mother in hospital and the number of days the child remained in hospital after birth were recorded. Details were also kept of certain aspects of the child's home environment, including the place in the family, the type of feeding instituted, the social class, and the housing standard and general hygiene of the home. This basic information and the bacteriological findings were coded for computer analysis.

\section{Results}

From Fig. 1 it can be seen that the frequency of isolation of $E$. coli reached its peak $(40 \%)$ among the samples taken at 21 days; thereafter, there is a steady fall to between 0 and $13 \%$ in the second year of life. The isolation rate for Klebsiella spp., $H$. influenzae and 'other coliforms' remained consistently low throughout the investigation. In fact, $H$. influenzae was very rarely isolated, but the isolation rate for other species of Haemophilus fluctuated between 0 and $13 \%$, and such isolations appeared to increase rather than decrease during the second year of life. Organisms grouped as 'other potential pathogens' included Pneumococcus, $\beta$-haemolytic Streptococcus and Staphylococcus aureus; their isolation rate varied between 1 and $12 \%$ over the same period.

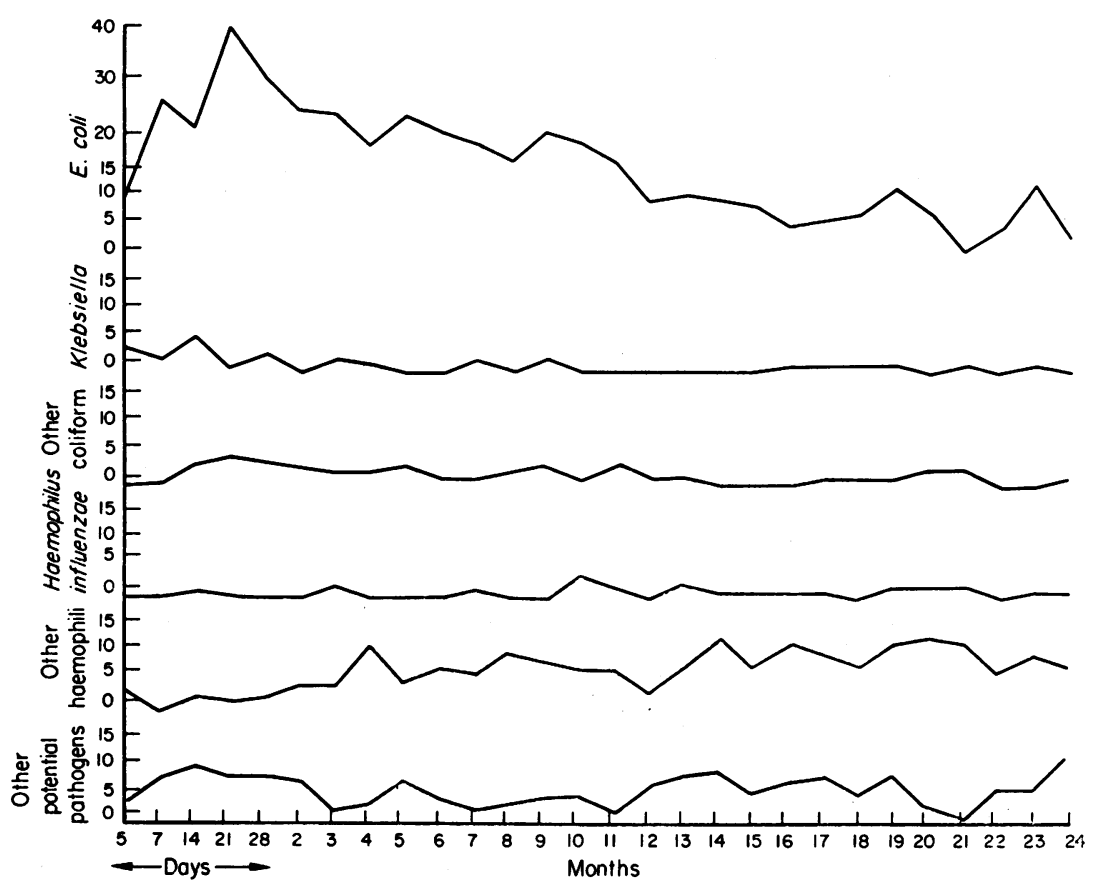

FIG. 1. Frequency $(\%)$ of isolation of organisms during survey. 
In Fig. 2 the isolation rate of $E$. coli is plotted against the months of the year, and apart from an isolated peak in December the rate remains fairly constant. The graph does not follow the seasonal pattern of respiratory infections established by McCall and Acheson (1968) but the absence of a seasonal impact may well be explained by the finding that certain children are habitually colonized by $E$. coli, some are intermittently so and others never. A seasonal influence would hardly be expected if $E$. coli colonization resulted from some peculiarity of 'seed and soil'. As the investigation proceeded, it was concluded that colonization of the upper respiratory tract by $E$. coli is by no means rare; in fact, less than $33 \%$ of the children failed to produce $E$. coli in their respiratory secretions at some time during the study, and so it was decided to divide the children into three groups.

Group A, those who produced $E$. coli in eight or more of the possible sixteen routine specimens taken in the first year of life. There were fourteen such children $(15.5 \%$ of the total);

Group B, those who produced $E$. coli in one to seven specimens. Forty-seven children $(52.2 \%)$;

Group $\mathrm{C}$, those who never produced $E$. coli. Twenty-nine children $(32 \cdot 2 \%)$.

These three groupings having been established, each was examined in relation to each of the factors listed above. The small numbers of cases in some sub-divisions did not allow statistical assessment of significance, but certain trends were evident. Table 1 reveals one of the most interesting findings of this study; the mothers of children in Group A had lyingin times more than three times as long as mothers of children in the other two groups. Again, Group A children spent considerably longer in hospital than the average. The proportion of children in Group A born by Caesarean section was higher than expected, but the numbers involved were very small and it was felt that this was more likely to result from a longer post-natal stay in hospital than on the type of delivery. In only three cases was the delivery assisted by instruments. It did not appear that the way in which membranes ruptured had any effect on postnatal colonization. All home confinements were at or about full term and therefore only hospital confinements could be used to see whether maturity had an effect on the three groupings. In fact, Group A contained a much higher percentage of premature babies than did either of the other two. This, of course, may once again be related to the length of stay in hospital since infants born prematurely may be expected to remain longer in hospital.

The three groups were assessed in relation to the

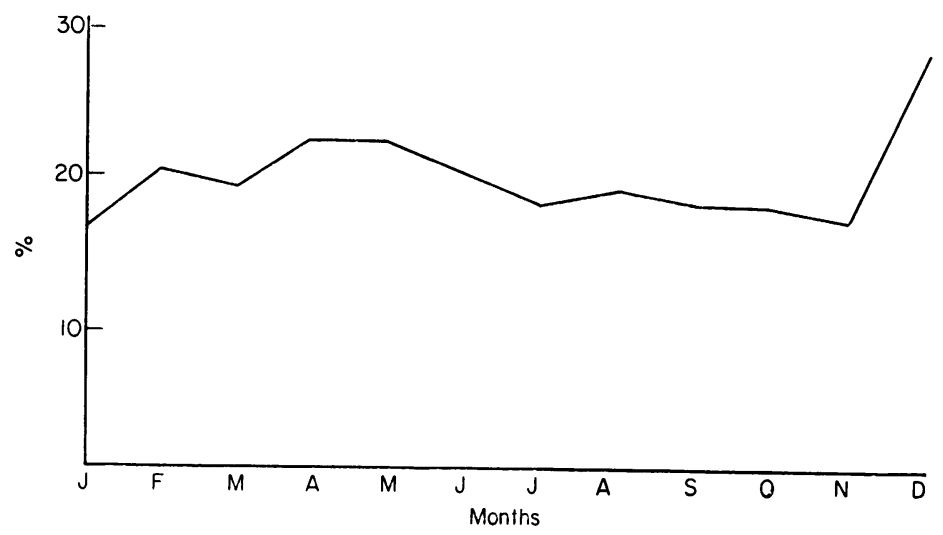

FIg. 2. Percentage positive for $E$. coli.

TABLE 1. Groups related to hospital confinement factors

\begin{tabular}{lccc}
\hline & Group A & Group B & Group C \\
\hline Confined in hospital & $11(78 \cdot 6 \%)$ & $32(68 \%)$ & $15(52 \%)$ \\
Ante-natal days in hospital (average) & $5 \cdot 4$ & $1 \cdot 5$ & $1 \cdot 4$ \\
Infant days in hospital (average) & $9 \cdot 0$ & $6 \cdot 2$ & 6.6 \\
Full-term confinements & $6(54 \cdot 5 \%)$ & $18(56 \cdot 2 \%)$ & $8(53 \cdot 4 \%)$ \\
Premature confinements & $4(36 \cdot 3 \%)$ & $5(15 \cdot 6 \%)$ & $3(20 \%)$ \\
Post-mature confinements & $1(9 \cdot 2 \%)$ & $9(28.2 \%)$ & $4(26.6 \%)$ \\
Home confinements* & 3 & 15 & 14 \\
\hline
\end{tabular}

* All were normal full-term SVD. 
feeding method adopted by the mother, i.e. whether breast feeding was established, given only a few days' trial, or not attempted. It was interesting to find an above-average number of established breast feeders among Group A children. This might be attributable to maternal factors, or it may reflect the fact that these infants spent a rather longer time in hospitaltheir average stay was 8 days compared with 6.8 days for the series as a whole.

Having analysed the pattern of colonization by Gram-negative bacilli in these children in health, attention was turned to the respiratory infections from which they suffered in their first 2 years of life. These episodes of respiratory infection, 285 in all, were classified on a simple clinical basis suggested by Carré (1961) and by Court (1968).

\begin{tabular}{clr}
\hline Type & \multicolumn{1}{c}{ Clinical diagnosis } & No. \\
\hline Type 1 & Upper respiratory tract infections & 135 \\
Type 2 & Laryngitis & 25 \\
Type 3 & Bronchitis & 123 \\
Type 4 & Bronchiolitis and pneumonias & 2 \\
Total of respiratory infections & 285 \\
\hline
\end{tabular}

Upper respiratory tract infections and bronchitis were by far the commonest types encountered. There were only two episodes of Type 4, both bronchopneumonias, and treated in hospital with broadspectrum antibiotics. One case was from Group B and the other Group C; both came from substandard houses with overcrowding, and it is worthwhile recording that $E$. coli was not cultured from the cough swabs taken on their discharge from hospital.

Figure 3 shows a steadily declining incidence of upper respiratory infection and bronchitis in the first 2 years of life, but the incidence of laryngeal infec- tions is more constant. In Fig. 4 there is the expected winter peak in the seasonal variations, with a smaller upsurge for bronchitis in the late spring and early summer, and an August/September increase for upper respiratory tract infections coinciding with the return of older siblings to school.

In Table 2 it can be seen that the episode rate for upper respiratory tract infections in the first 2 years is lowest in Group A. The percentage of each group which did not suffer any upper respiratory tract infection is remarkably constant, whereas recurring episodes (two or more) are shown to be more common in Groups B and C.

The bronchitis figures reveal an even greater discrepancy, the Group A episode rate in the first 2 years being less than half that of the other two groups. Again, recurring episodes of bronchitis are more common in Groups B and C.

Table 3 relates the groups' social environments and the incidence of respiratory infections. Of the fourteen cases in the substandard houses of the miners' row there is a higher percentage of Group $\mathrm{C}$ children than would be expected, while the distribution of Groups A, B and C children in the satisfactory council and private houses follows that of the survey as a whole. On further investigation, nine of these fourteen cases proved to be home confinements and this may be a factor in producing the high percentage of infants in Group C, since infants born at home tended not to be colonized by Gram-negative bacilli. When the incidence of chest infections is related to housing standards, the upper respiratory tract infection rate per child for the first 2 years is reasonably constant, but there is a significant increase in the rates for laryngitis and bronchitis in the substandard miners' row houses. The hygiene of the home was also considered, and a visual assessment of the 'living'

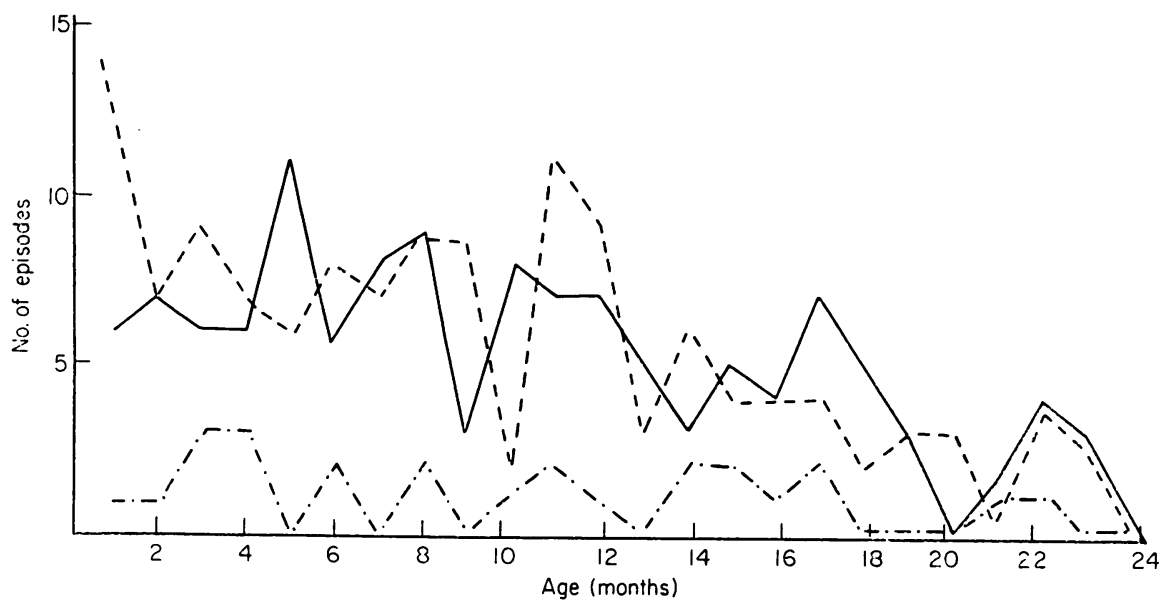

FIG. 3. URTI, ---; laryngitis, - - - - ; bronchitis, - . 


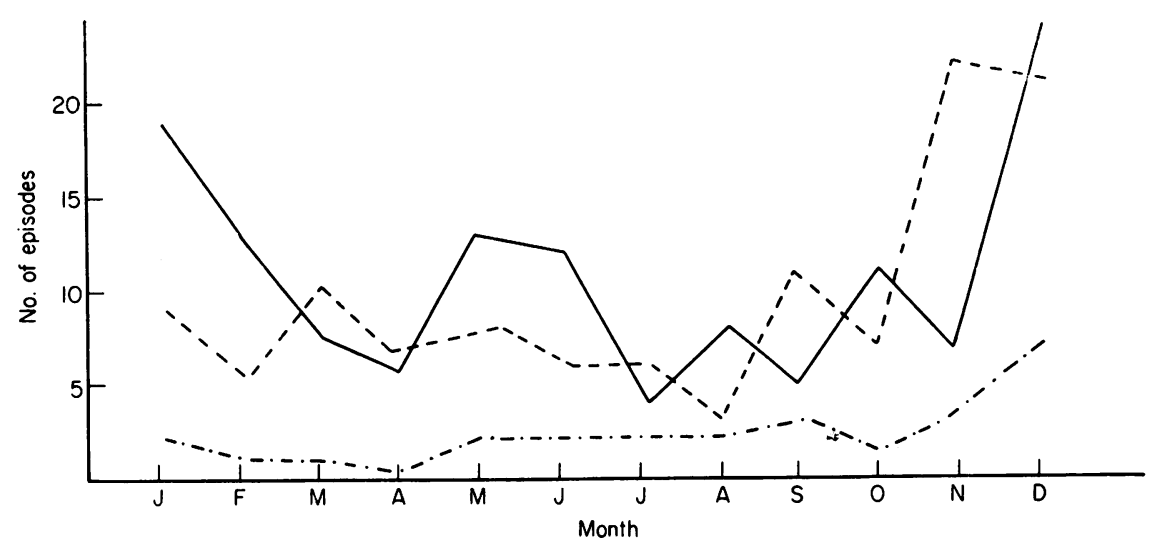

FIG. 4. URTI, ---; laryngitis, - - - - ; bronchitis, -

TABLE 2. Groups in relation to most frequent respiratory infections (Types 1 and 3)

\begin{tabular}{|c|c|c|c|c|c|}
\hline \multirow[b]{2}{*}{ Type } & \multirow[b]{2}{*}{ Group } & \multirow{2}{*}{$\begin{array}{l}\text { Episodes in first } 2 \text { years } \\
\text { (rate/child in brackets) }\end{array}$} & \multicolumn{3}{|c|}{$\begin{array}{c}\text { Frequency of episodes } \\
\text { (percentage of group in brackets) }\end{array}$} \\
\hline & & & 0 episode & 1 episode & $>2$ episodes \\
\hline $\begin{array}{c}1 \\
\text { (URT) }\end{array}$ & $\begin{array}{l}\text { A } \\
\text { B } \\
\text { C }\end{array}$ & $\begin{array}{ll}17(1 \cdot 2) \\
74(1 \cdot 57) \\
44(1 \cdot 55)\end{array}$ & $\begin{array}{r}3(21.4 \%) \\
10(21.3 \%) \\
6(20.7 \%)\end{array}$ & $\begin{aligned} 7 & (50 \%) \\
18 & (38.3 \%) \\
8 & (27.6 \%)\end{aligned}$ & $\begin{array}{r}4(28.6 \%) \\
19(40.4 \%) \\
15(51.7 \%)\end{array}$ \\
\hline $\begin{array}{c}3 \\
\text { (Bronchitis) }\end{array}$ & $\begin{array}{l}\text { A } \\
\text { B } \\
\text { C }\end{array}$ & $\begin{aligned} 9 & (0 \cdot 64) \\
64 & (1 \cdot 36) \\
48 & (1 \cdot 7)\end{aligned}$ & $\begin{aligned} 7(50 \%) \\
18(38 \cdot 3 \%) \\
12(41.4 \%)\end{aligned}$ & $\begin{array}{r}4(28.6 \%) \\
13(27.7 \%) \\
4(13.8 \%)\end{array}$ & $\begin{aligned} 3 & (21.4 \%) \\
16 & (34 \%) \\
13 & (44.8 \%)\end{aligned}$ \\
\hline
\end{tabular}

TABLE 3. Groups, social environmental factors, and respiratory infections

\begin{tabular}{|c|c|c|c|c|c|c|}
\hline & \multicolumn{3}{|c|}{ Children (no. and $\%$ ) } & \multicolumn{3}{|c|}{$\begin{array}{l}\text { Total episodes of respiratory } \\
\text { infection types and rate per child }\end{array}$} \\
\hline & Group A & Group B & Group C & URTI & Laryngitis & Bronchitis \\
\hline \multicolumn{7}{|l|}{ Housing } \\
\hline Miners' row & $1(7 \cdot 1 \%)$ & $7(50 \%)$ & $6(42.9 \%)$ & $21(1.5 \%)$ & $6(0.43 \%)$ & $33(2 \cdot 36 \%)$ \\
\hline Private and council & $12(16.6 \%)$ & $38(52 \cdot 7 \%)$ & $22(30.6 \%)$ & $105(1.46 \%)$ & $18(0.25 \%)$ & $89(1.23 \%)$ \\
\hline Farm & $1(25 \%)$ & $2(50 \%)$ & $1(25 \%)$ & $9(2 \cdot 25 \%)$ & $1(0.25 \%)$ & $1(0.25 \%)$ \\
\hline \multicolumn{7}{|l|}{ Hygiene } \\
\hline Good & $12(18 \cdot 7 \%)$ & $29(45 \cdot 3 \%)$ & $23(36 \%)$ & $94(1.47 \%)$ & $13(0.2 \%)$ & $80(1.25 \%)$ \\
\hline Poor & $2(7 \cdot 7 \%)$ & $18(69 \cdot 2 \%)$ & $6(22 \cdot 2 \%)$ & $41(1 \cdot 51 \%)$ & $12(0.46 \%)$ & $43(1.64 \%)$ \\
\hline \multicolumn{7}{|l|}{ Family size } \\
\hline 1 & $8(26.6 \%)$ & $17(56.6 \%)$ & $5(16 \cdot 8 \%)$ & $44(1.5 \%)$ & $10(0.33 \%)$ & $32(1 \%)$ \\
\hline 2 & $4(13.9 \%)$ & $11(38 \%)$ & $14(48 \cdot 1 \%)$ & $35(1.19 \%)$ & $3(0.1 \%)$ & $40(1.38 \%)$ \\
\hline 3 & $1(7.6 \%)$ & $7(54.6 \%)$ & $5(46.8 \%)$ & $21(1.61 \%)$ & $4(0.31 \%)$ & $22(1.7 \%)$ \\
\hline 4 or more & $1(5 \cdot 5 \%)$ & $12(67 \cdot 7 \%)$ & $5(27.7 \%)$ & $35(1.95 \%)$ & $8(0.44 \%)$ & $29(1.61 \%)$ \\
\hline \multicolumn{7}{|l|}{ Social class } \\
\hline $1,2,3$ & $11(19 \cdot 5 \%)$ & $26(45.4 \%)$ & $20(35 \cdot 1 \%)$ & $88(1.54 \%)$ & $11(0.2 \%)$ & $76(1.33 \%)$ \\
\hline 4,5 & $3(9 \cdot 1 \%)$ & $21(63.6 \%)$ & $9(27.3 \%)$ & $47(1.42 \%)$ & $14(0.42 \%)$ & $47(1.42 \%)$ \\
\hline
\end{tabular}

rooms in each home was made. Table 3 shows that $18.7 \%$ of the children from homes of good hygiene are in Group A, as compared with only $7.7 \%$ of children from homes of poor hygiene. No less than $69.2 \%$ of the children from homes of poor hygiene are in Group B, i.e. the group who were colonized by $E$. coli on an intermittent pattern. This is of interest because the episode rate for laryngitis and bronchitis is higher in homes of poor hygiene. The steady fall in the percentage of children in Group A as family size increases is a noteworthy corollary to the rising overall rate of respiratory infection among larger families.

The groups' respiratory infections were also considered by Social Class (Registrar-General's classification). Figures for Social Classes 1, 2 and 5 are 
small (1, 3 and 7 respectively) but a convenient grouping of Class 1 and 2 with 3 , and Class 4 with 5 was made to compare the groups and their respiratory infection rate. As previously demonstrated by Fry (1961) and Brimblecombe et al. (1958), there is a higher episode rate of respiratory infection in the lower classes. In these classes in the present survey the percentage of Group A children is less than half that in the higher classes, and in the former a higher percentage of Group B children is to be noted. This result appears to have been influenced by other factors such as poor home hygiene, lower housing standards and increasing family size.

Table 4 shows the frequency with which antibiotics were used in various types of respiratory infection. The broad-spectrum group includes ampicillin and sulphonamides, and the narrow-spectrum group penicillin $\mathrm{V}$ and erythromycin.

From Table 5 it can be seen that on fifty-tour occasions $E$. coli was cultured at the onset of a respiratory infection. Samples at the beginning of the illness were collected in 244 of the 285 episodes $(85 \%)$ and this gives an $E$. coli isolation rate of $22 \cdot 1 \%$.
Table 6 summarizes the number of $E$. coli isolations from specimens taken at the onset and at the end of each incident of respiratory infection, in relation to the type of antibiotic therapy employed. It is evident that the use of antibiotics certainly did not result in an increase in the isolation rate of $E$. coli; in fact, the reverse is true although it has to be noted that the fall in the isolation rate is greater where no antibiotic was used than where either a broad- or narrow-spectrum antibiotic was exhibited.

\section{Source of respiratory E. coli}

As the work proceeded, it was decided to search for a source of the coliform bacilli being found in the respiratory tract of the infants. Both host and environmental factors which influence the establishment of the neonatal bacterial flora have been painstakingly examined by Evans, Akpata and Baki (1970). They cite the general view that the birth canal is unimportant as a source of respiratory flora in the early days of life, although Benirschke (1960) reported evidence that the bacteria cultured from the vagina and those from the infant's respiratory tract

TABLE 4. Antibiotics used in different types of infection

\begin{tabular}{lcccc}
\hline & \multicolumn{4}{c}{ Antibiotic } \\
\cline { 2 - 4 } Respiratory infection & None & Broad-spectrum & Narrow-spectrum & Total \\
\hline URTI & 97 & 4 & 34 & 135 \\
Laryngitis & 7 & 1 & 17 & 25 \\
Bronchitis & 6 & 27 & 90 & 123 \\
Pneumonias & 0 & 2 & 0 & 2 \\
All infections & $110(38 \%)$ & $34(12 \%)$ & $141(50 \%)$ & $285(100 \%)$ \\
\hline
\end{tabular}

TABLE 5. Organisms isolated at onset of different types of respiratory infection. (More than one organism isolated from certain episodes)

\begin{tabular}{|c|c|c|c|c|c|c|c|}
\hline Infection & Commensals & E. coli & Klebsiella & $\begin{array}{l}\text { Other } \\
\text { coliform }\end{array}$ & $\begin{array}{c}\text { Haem. } \\
\text { influenzae }\end{array}$ & $\begin{array}{c}\text { Other } \\
\text { haemophilus }\end{array}$ & $\begin{array}{c}\text { Other } \\
\text { potential } \\
\text { pathogens }\end{array}$ \\
\hline $\begin{array}{l}\text { URTI } \\
\text { Laryngitis } \\
\text { Bronchitis }\end{array}$ & $\begin{array}{l}86(58 \%) \\
15(53.5 \%) \\
83(63.8 \%)\end{array}$ & $\begin{aligned} 25 & (17 \%) \\
6 & (21.5 \%) \\
23 & (17.6 \%)\end{aligned}$ & $\begin{array}{l}2(1.4 \%) \\
0(0 \%) \\
0(0 \%)\end{array}$ & $\begin{array}{l}6(4.2 \%) \\
2(7 \cdot 2 \%) \\
3(2.3 \%)\end{array}$ & $\begin{array}{l}4(2 \cdot 8 \%) \\
0(0 \%) \\
3(2 \cdot 3 \%)\end{array}$ & $\begin{array}{r}11(7.4 \%) \\
2(7.2 \%) \\
8(6.3 \%)\end{array}$ & $\begin{aligned} 14 & (9.2 \%) \\
3 & (10.6 \%) \\
10 & (7.7 \%)\end{aligned}$ \\
\hline
\end{tabular}

TABLE 6. E. coli isolations from specimens in relation to the use of antibiotics in respiratory infections

\begin{tabular}{lcccccc}
\hline & \multicolumn{2}{c}{ Respiratory infection onset } & & \multicolumn{2}{c}{ Respiratory infection end } \\
\cline { 2 - 3 } \cline { 5 - 6 } \multicolumn{1}{c}{ Antibiotic } & $\begin{array}{c}E . \text { coli } \\
\text { present }\end{array}$ & $\begin{array}{c}\text { E. coli } \\
\text { absent }\end{array}$ & & $\begin{array}{c}\text { E. coli } \\
\text { present }\end{array}$ & $\begin{array}{c}\text { E. coli } \\
\text { absent }\end{array}$ \\
\hline None & 18 & & 76 & & 12 & 82 \\
Broad-spectrum & 8 & 22 & & 7 & 23 \\
Narrow-spectrum & 27 & 93 & & 23 & 97 \\
\hline
\end{tabular}


are usually identical. Gareau et al. (1959) studied twenty mothers and their infants and found that $25 \%$ of the infants had the same faecal flora as their mothers, whereas only $10 \%$ harboured the same serotype in their throats. No evidence has been found for transfer of organisms from infected maternal urine to the newborn child. Because serological typing of $E$. coli is more refined than methods available for most of the other Gram-negative bacilli being isolated, attention was focused on this particular species.

With these points in mind, the following specimens were examined for the presence of $E$. coli.

(a) Mother-(1) faeces and (2) urine immediately before the first stage of labour (sometimes several specimens had to be examined and the latest results were used); (3) high vaginal swab during the first stage of labour; (4) faeces and (5) high vaginal swab soon after delivery.

(b) Infant-cough swabs were taken in the same way and at the same intervals of time as described above. In most cases, samples of faeces were collected in the first 7-10 days of life. In cases where $E$. coli had been isolated from two or more of the routine first five cough swabs, attempts were made to repeat these examinations at 2 and 3 months of age. Additional cough swabs were also taken when an infant developed a respiratory illness.

\section{Serology}

Five representative lactose-fermenting colonies which morphologically resembled $E$. coli were individually subcultured and tested for production of acid and gas from glucose and lactose, production of indole, and failure to utilize Simmon's citrate or to split urea. They were subcultured to nutrient agar, and a homogeneous suspension was made by harvesting the growth in $0.85 \%$ sodium chloride solution. The bacterial suspension was then boiled for $30 \mathrm{~min}$. Overnight incubation at $50^{\circ} \mathrm{C}$ was used for titration of $0.5 \mathrm{ml}$ samples of the suspension against $0.5 \mathrm{ml}$ samples of the following fifty commercially prepared sera: 01, 02, 03, 04, 05, 06, 07, 08, 09, 010, 011, 012, 013, 014, 015, 016, 017, $018: \mathrm{B} 20,018$ : B21, 019, 020 : B7, $020: 84(\mathrm{~B}), 021,022,023,024,025,026$ : B6, 028 : B18, 039, 044 : K74, 045, 055 : B5, 062, 068, 075, $086: \mathrm{B} 7,0102,0111: \mathrm{B} 4,0112: \mathrm{B} 11$, 0112 : B13, 0113 : B19, 0119 : B14, $0124:$ : 17 , $0125: \mathrm{B} 15,0126: \mathrm{B} 16,0127: \mathrm{B} 8,0128: \mathrm{B} 12$, 0136 : B22, and 0140.
A total of 189 specimens from seventeen mothers and their infants were examined for $E$. coli, and 600 colonies were serotyped. In five instances the serotype present in the infant's respiratory tract corresponded to that found in the mother's antenatal specimens (usually faeces). In ten, non-typeable strains were found in both mother and infant specimens, and in the remaining two the infants harboured serotypes not found in the mother's ante-natal specimens. It was disappointing to find that, despite the use of a fairly extensive range of typing sera, just over $50 \%$ of the cases harboured non-typeable strains of E. coli. Grüneberg and Bettelheim (1969), using 147 sera, were able to type nearly $90 \%$ of their $E$. coli isolates from infected urine. Nevertheless, it could be argued from the consistency seen in the typeable strains from certain cases that the regular occurrence of non-typeable strains in others is possibly significant, and that the use of a wider range of sera would have revealed more examples of the same serotype being harboured by both mother and child. The serotypes found in this investigation corresponded closely to those most frequently encountered in eleven other surveys of $E$. coli isolated from urinary tract infections (Grüneberg and Bettelheim, 1969).

The absence of serotype 075 from this series may simply reflect the geographical variations in the 0 . group distribution of $E$. coli which are known to occur.

No firm conclusion can be offered as to the source of the $E$. coli in the infants' respiratory flora. Vaginal isolates of $E$. coli were very infrequently made and the authors would support the view that the birth canal is not an important source of respiratory organisms in the newborn child. What evidence there is suggests that the maternal bowel content is a much more likely source. Once established, however, a particular serotype may colonize the respiratory tract for some weeks or even months.

\section{Discussion}

The purpose of this investigation was to try to reassess the significance of $E$. coli and other Gramnegative bacilli in the upper respiratory secretions of young children. At the outset, the authors shared the previously expressed doubts regarding the clinical significance of the often predominantly Gramnegative bacillary flora found on culture of these secretions from young children suffering from chest infections. These investigations have shown that

\begin{tabular}{lrrrrrrrrrrr}
\hline Serotype & 01 & 02 & 04 & 06 & 07 & 08 & 09 & 011 & 018 & 039 & 075 \\
\hline Eleven other series & 137 & 79 & 209 & 208 & 89 & - & 18 & 19 & 51 & 5 & 134 \\
This series & 1 & 1 & 1 & 2 & - & 2 & 2 & 3 & 2 & 1 & - \\
\hline
\end{tabular}


colonization by Gram-negative bacilli is by no means rare; in fact, only about $33 \%$ of healthy children are unlikely to harbour such organisms in their upper respiratory tracts at some time in their first year of life. In approximately $16 \%$ of the survey children up to 1 year of age, colonization is the rule rather than the exception, particularly when the principal Gramnegative bacillus harboured is $E$. coli. Serotyping was performed mainly on strains isolated in the early months of life and it has not been proved, nor is it suggested, that the same serotype necessarily persists throughout the whole of the first year-the work of Cooke et al. (1972) on ingested $E$. coli would suggest that this is rather unlikely. Other Gram-negative bacilli behave differently, organisms such as Proteus, Klebsiella and Paracolon bacilli seldom appearing in several consecutive examinations.

One of the most interesting results from the study was the obvious link between $E$. coli colonization and duration of stay in hospital at the time of birth. Not only did the Group A infants themselves spend longer in hospital, but their mothers' ante-natal hospital stay was between three and four times as long as that of the other mothers. Maternity units have, for at least a decade, used hexachlorophane to reduce the incidence of staphylococci. Forfar, Gould and MacCabe (1968) have pointed out that Gramnegative bacilli have displaced Gram-positive cocci as causes of minor infections in such units, and that the balance of the bacterial flora of the hospital environment is also altered by the widespread use of hexachlorophane. This policy may well continue, although in admittedly modified ways because of the anxiety expressed by Curley et al. (1971) about the use of hexachlorophane preparations for infant bathing and dusting. These facts suggest that the infants who spend the longest time in the hospital environment, where Gram-negative bacilli may predominate and may be present on the hands of nurses and mothers, are much more likely to have the respiratory tract colonized by such organisms. The possibility of transfer of organisms from the mothers' skin during the close contact of breast feeding has also to be considered; although the numbers are too small to establish any firm conclusion, it is interesting to note that Group A babies had a higher incidence of established breast feeding than the others. Maternal influence is also seen in five of the cases examined serologically where the same serotype was found in the infants' respiratory secretions as in the mothers' faeces. As already stated, this endorses the view that the genital tract is not a source of Gramnegative organisms during the infant's passage through it; transfer of organisms from the perineum at birth, or during handling by the mother after birth, appears to be a more probable explanation.

Another factor which might have influenced the infants' respiratory flora was an alteration in the mothers' commensals as a consequence of administration of antibiotics, especially broad-spectrum antibiotics. In fact, their use in labour was extremely scant, four cases receiving a broad-spectrum antibiotic and one a urinary antiseptic in the last week of gestation, and the numbers are too small to allow other than negative conclusions to be drawn; there is certainly no evidence that their use predisposes to later colonization by Gram-negative bacilli. None of the infants in Group A received antibiotics in hospital.

An intriguing fact which emerged was that, irrespective of housing standards, place in family and social class, Group A children (those habitually colonized by $E$. coli) were less frequently affected by upper respiratory tract infections and bronchitis, illnesses which in this age group nearly always have a viral aetiology. Grossberg (1972) described a nonsedimentable protein obtained from certain strains of $E$. coli which was a potent inducer of antiviral resistance and interferon, and it is interesting to speculate on the possibility that $E$. coli colonization, far from being potentially pathogenic, actually exerts a protective effect.

Unfavourable environmental factors such as bad housing, poor home hygiene, increasing family size and low social class are all associated with an 'intermittent' pattern of $E$. coli colonization (Group $B)$, and these circumstances are linked with a higher episode rate of respiratory infection.

No evidence was found that the administration of antibiotics, broad- or narrow-spectrum, influenced colonization by Gram-negative bacilli. Their use was very limited indeed immediately before delivery and in the post-partum period, and even when antibiotics were administered to children with respiratory infections the post-treatment specimens did not prove to have a significantly greater incidence of Gram-negative bacilli. It is concluded that colonization by these organisms is more related to other factors, some of which are cited in the present report, than to the use of antibiotics.

The authors failed to detect in the respiratory tracts of young children particular serotypes of $E$. coli which regularly had a pathogenic effect corresponding to the well recognized type-specific strains associated with infantile gastro-enteritis. The overall data on the pathogenicity of $E$. coli, however, could be interpreted in two ways. When cases of respiratory illness were considered, $E$. coli was isolated at the onset in $22.1 \%(54 / 244)$, whereas in routine examinations of healthy children it was found in only $17 \cdot 1 \%$ (397/2321). Although a pathogenic role for $E$. coli might appear to be suggested, it has to be noted that the two samples are very unequal in size. On the other hand, if the last routine samples taken before 
the onset of illness are considered, $E$. coli was isolated in $12.9 \%(33 / 258)$ of the whole series, but in $35 \%$ and $15 \%$ of Group A and Group B children respectively. Once again the sample sizes are very unequal but the figures could suggest that the disappearance of $E$. coli from the upper respiratory tract may, in certain cases, precede the onset of respiratory illness. This hypothesis would be in agreement with the 'anti-viral' or 'protective' theory propounded by Grossberg (1972) referred to above. The latter concept is more easily reconciled with the generally accepted view that $E$. coli is not a primary respiratory pathogen in previously healthy adults; in the series of $E$. coli pneumonias described by Tillotson and Lerner (1967) one or more serious chronic diseases were present, presumably providing conditions for E. coli to play the part of an 'opportunist' invader. Bacteria with an accepted aetiological role in respiratory disease, such as Pneumococcus and $H$. influenzae, were seldom isolated in the present survey. An interesting finding, however, was the frequency with which haemolytic strains of Haemophilus were encountered, and several children regularly harboured such strains for several months, apparently without ill-effect. It is concluded that haemolytic stains of Haemophilus spp., especially in mixed culture, should not be regarded as pathogenic, and laboratories should not risk misleading the clinician by reporting sensitivity results on respiratory isolates. Branson (1968) found $H$. parahaemolyticus in $18 \%$ of her control series when investigating the clinical significance of haemolytic Haemophilus in the throat, and Parsons and Faris (1973) noted that there had been very few previous reports of $H$. parahaemolyticus as a pathogen and none of it as a pyogenic organism.

\section{Acknowledgments}

We would like to thank Drs G. R. Brown, J. Syme and R. G. Whitelaw for allowing us access to their patients in Dunfermline Maternity Hospital. The purchase of serological reagents was made possible by a grant from the Secretary of State for Scotland on the recommendation of the Advisory Committee on Medical Research; for this we are grateful. We acknowledge, with thanks, the advice and assistance received from the Data Processing Department of the SouthEastern Regional Hospital Board, in particular Miss Farquhar. Our thanks are also due to Mrs I. Sneddon who typed the manuscript, and to $\mathrm{Mr} \mathrm{W}$. D. McIntyre who supplied prints of the figures. By courtesy of Dr Joan Taylor and Dr Bernard Rowe, one of us (J.D.B.) was able to gain experience of serotyping techniques at the Central Public Health Laboratory, Colindale. Their helpful advice and the ready co-operation of their technical staff was greatly appreciated.

\section{References}

BeniRsChKe, K. (1960) Routes and types of infection in the fetus and the newborn. American Journal of Diseases of Children, 99, 28.
BRANSON, D. (1968) Bacteriology and clinical significance of hemolytic Haemophilus in the throat. Applied Microbiology, 16, 256.

Brimblecombe, F.S.W., Cruickshank, R., Masters, P.L., ReID, D.D. \& STewart, G.T. (1958) Family studies of respiratory infections. British Medical Journal, i, 119.

CARRÉ, I.J. (1961) The acute respiratory infections of childhood. Practitioner, 187, 767.

Cooke, E. Mary, Hettiaratchy, Ira G.T. \& Buck, A.C. (1972) Fate of ingested Escherichia coli in normal persons. Journal of Medical Microbiology, 5, 361.

CourT, S.D. (1968) Epidemiology and natural history of respiratory infections in children. Journal of Clinical Pathology, 21, Suppl. 2, 30.

Curley, A., Hawk, R E., Kimbrough, R D., Nathenson, G. \& FinBerG, L. (1971) Dermal absorption of hexachlorophane in infants. Lancet, ii, 296.

Elderkin, F.M., Gardner, P.S., Turk, D.C. \& White, ANITA C. (1965) Aetiology and management of bronchiolitis and pneumonia in childhood. British Medical Journal, ii, 722.

Evans, H.E., Akpata, S.O. \& BaKi, A. (1970) Factors influencing the establishment of the neonatal bacterial flora. Archives of Environmental Health, 21, 514.

Farmer, Keitha (1968) The influence of hospital environment and antibiotics on the bacterial flora of the upper respiratory tract of the newborn. New Zealand Medical Journal, 67, 541.

Forfar, J.O., Gould, J.C. \& MaCCaBe, A.F. (1968) Effect of hexachlorophane on incidence of staphylococcal and Gram-negative infection in the newborn. Lancet, ii, 177.

Fry, J. (1961) The Catarrhal Child, 1st edn, p. 41. Butterworth, London.

Gareau, Florence E., Mackel, D.C., Boring, J.R., Payne, F.J. \& HammetT, Frances L. (1959) The acquisition of fecal flora by infants from their mothers during birth. Journal of Pediatrics, 54, 313.

GrossberG, S.E. (1972) The interferons and their inducers: molecular and therapeutic considerations. New England Journal of Medicine, 287, 13.

GrüneberG, R.N. \& Bettelheim, K.A. (1969) Geographical variations in serological types of urinary Escherichia coli. Journal of Medical Microbiology, 2, 219.

LidWell, O.M. \& Sommerville, T. (1951) Observations on the incidence and distribution of the common cold in a rural community during 1948 and 1949. Journal of Hygiene, 49, 365.

McCall, M.G. \& ACheson, E.D. (1968) Respiratory disease in infancy. Journal of Chronic Diseases, 21, 349.

Parsons, M. \& Faris, I. (1973) Empyema of the gallbladder due to Haemophilus parahaemolyticus with a brief review of its role as a pathogen. Journal of Clinical Pathology, 26, 604.

Shallard, M.A. \& Williams, A.L. (1966) Studies on Gramnegative bacilli in a ward for newborn babies. Medical Journal of Australia, 2, 455.

Tillotson, J.R. \& LeRner, A.M. (1967) Characteristics of pneumonias caused by Escherichia coli. New England Journal of Medicine, 277, 115.

Topley, K. \& Wilson, J. (1964) Principles of Bacteriology and Immunity, 5th edn, p. 2475. Edward Arnold: London.

Wilson, M.J.B. \& Martin, D.E. (1972) Quantitative sputum culture as a means of excluding false positive reports in the routine microbiology laboratory. Journal of Clinical Pathology, 25, 697. 